\title{
Fatal toxicity of serotoninergic and other antidepressant drugs: analysis of United Kingdom mortality data
}

\author{
Nicholas A Buckley, Peter R McManus
}

Department of

Clinical

Pharmacology and

Toxicology,

Canberra Hospital,

PO Box 11, Woden,

ACT 2606,

Australia

Nicholas A Buckley

associate professor

continued over

BMJ 2002;325:1332-3

Several studies over the past 15 years have compared the number of fatal poisonings due to antidepressant drugs in the United Kingdom with drug use statistics to derive a fatal toxicity index: deaths per million prescriptions. ${ }^{12}$ Greater than 10 -fold differences in the index have been shown between tricyclic antidepressants and even larger differences between some tricyclics and newer antidepressants. Explanations have focused on preference for noradrenaline or serotonin reuptake blockade, although only weak correlations have been observed ${ }^{2}$ and the explanation is toxicologically implausible. ${ }^{1}$ In the late 1990 s the use of newer serotoninergic antidepressants increased dramatically. Some data show that venlafaxine in particular may not be as safe in overdose as other

Fatal toxicity index (deaths per million prescriptions) for antidepressants ranked within British National Formulary classes

\begin{tabular}{|c|c|c|c|}
\hline Drug & $\begin{array}{c}\text { No of } \\
\text { prescriptions } \\
\text { (thousands) }\end{array}$ & Total deaths & $\begin{array}{c}\text { Deaths/million } \\
\text { prescriptions }(95 \% \mathrm{Cl})\end{array}$ \\
\hline $\begin{array}{l}\text { Tricyclic antidepressants and related } \\
\text { drugs: }\end{array}$ & 74598 & 2598 & 34.8 (33.5 to 36.2 ) \\
\hline Desipramine & 45 & 9 & 200.9 (92.0 to 381.6$)$ \\
\hline Amoxapine & 107 & 10 & 93.5 (44.8 to 171.8$)$ \\
\hline Dothiepin & 26210 & 1398 & 53.3 (50.5 to 56.1$)$ \\
\hline Amitriptyline & 23844 & 906 & 38.0 (35.5 to 40.5$)$ \\
\hline Imipramine & 3354 & 110 & 32.8 (27.0 to 39.5 ) \\
\hline Doxepin & 1587 & 40 & 25.2 (18.0 to 34.3 ) \\
\hline Trimipramine & 2370 & 39 & 16.5 (11.7 to 22.5$)$ \\
\hline Clomipramine & 4315 & 54 & 12.5 (9.4 to 16.3 ) \\
\hline Nortriptyline & 1269 & 7 & $5.5(2.2$ to 11.4$)$ \\
\hline Maprotiline & 201 & 1 & 5.0 (0.1 to 27.7$)$ \\
\hline Trazodone & 2753 & 11 & 4.0 (2.0 to 7.1$)$ \\
\hline Mianserin & 922 & 3 & 3.3 (0.7 to 9.5$)$ \\
\hline Mirtazapine & 324 & 1 & $3.1(0.1$ to 17.2$)$ \\
\hline Lofepramine & 7189 & 9 & $1.3(0.6$ to 2.4$)$ \\
\hline Butriptyline & 1 & 0 & 0 (0 to 3372$)$ \\
\hline Iprindole & 3 & 0 & 0 (0 to 1218) \\
\hline Viloxazine & 10 & 0 & 0 (0 to 357.2$)$ \\
\hline Protriptyline & 94 & 0 & 0 (0 to 39.2$)$ \\
\hline Serotoninergic drugs: & 47329 & 77 & 1.6 (1.3 to 2.0$)$ \\
\hline Venlafaxine & 2570 & 34 & 13.2 (9.2 to 18.5$)$ \\
\hline Fluvoxamine & 660 & 2 & $3.0(0.3$ to 10.9$)$ \\
\hline Citalopram & 2603 & 5 & $1.9(0.6$ to 4.5$)$ \\
\hline Sertraline & 5964 & 7 & $1.2(0.5$ to 2.4$)$ \\
\hline Fluoxetine & 19926 & 18 & $0.9(0.5$ to 1.4$)$ \\
\hline Paroxetine & 15031 & 11 & 0.7 (0.4 to 1.3$)$ \\
\hline Nefazodone & 576 & 0 & 0 (0 to 6.4$)$ \\
\hline Monoamine oxidase inhibitors: & 1203 & 24 & 20.0 (12.8 to 29.7$)$ \\
\hline Tranylcypromine & 367 & 16 & 43.6 (25.0 to 70.9$)$ \\
\hline Phenelzine & 404 & 6 & 14.9 (5.5 to 32.4$)$ \\
\hline Moclobemide & 365 & 2 & $5.5(0.6$ to 19.8$)$ \\
\hline Iproniazid & 0.2 & 0 & 0 (0 to 18444$)$ \\
\hline Isocarboxazid & 68 & 0 & $0(0$ to 54.6$)$ \\
\hline Other antidepressants: & 2523 & 1 & 0.4 (0 to 2.2$)$ \\
\hline Flupentixol & 2320 & 1 & 0.4 (0 to 2.4$)$ \\
\hline Tryptophan & 28 & 0 & 0 (0 to 133.3) \\
\hline Reboxetine & 175 & 0 & $0(0$ to 21.1$)$ \\
\hline Lithium & 5106 & 37 & $7.2(5.1$ to 10.0$)$ \\
\hline
\end{tabular}

Numbers may not add up to the total because of rounding. serotoninergic drugs, with reports of deaths, arrhythmias, and seizures. ${ }^{3}$ We aimed to establish the relative frequency with which venlafaxine and other new antidepressants result in fatal poisoning.

\section{Methods and results}

We obtained the number of deaths in Scotland, England, and Wales due to acute poisoning by a single drug, with or without co-ingestion of alcohol, from the General Register Office for Scotland and the Office for National Statistics for the years 1993-9. We used the number of prescription items for England, Wales, and Scotland supplied by the respective departments of health for these years as a measure of relative drug use. Use in hospital is not included, but prescribing of antidepressants overwhelmingly occurs in general practice. For each drug we calculated a fatal toxicity index expressed as deaths per million prescriptions. We calculated the lower and upper $95 \%$ confidence limits for the index by using exact confidence intervals for the deaths. ${ }^{1}$

The table lists the drugs in descending order of fatal toxicity index within British National Formulary drug classes. The serotoninergic drug class overall had a much lower index than the tricyclic antidepressants and monoamine oxidase inhibitors, but venlafaxine had a higher index than the individual and combined results of other serotoninergic drugs.

\section{Comment}

The most striking new observation is that the fatal toxicity index for venlafaxine is higher than those for other serotoninergic antidepressants and similar to those for some less toxic tricyclic antidepressants. This raises the question of whether venlafaxine should continue to be a first line drug in patients with suicidal ideation. Our results also confirm previously reported large differences in fatal toxicity index between other antidepressant drugs. ${ }^{12}$

This sort of analysis is open to several criticisms. ${ }^{1}$ Using the fatal toxicity index as a measure of lethality in overdose makes some assumptions, including that mortality data are not influenced by previous literature and that drugs are taken in overdose with similar frequency and in similar amounts. The perceived risk of overdose has the potential to confound by altering several variables. For example, "less toxic" drugs may be preferentially prescribed to patients at higher risk of poisoning and suicide, ${ }^{4}$ but they are also less likely to be listed as the sole cause of death from overdose.

Toxicity in overdose should be an important consideration in the choice of first line treatment but should be based on data for each individual drug and not on the therapeutic class or on measures such as serotonin or noradrenaline selectivity that do not directly lead to toxicity in overdose. Poisoning with antidepressants accounts for only about $4-7 \%$ of all suicides, but the proportion of suicides from antide- 
pressant poisoning in people prescribed antidepressants is much higher. ${ }^{5}$ Assuming that an average prescription is for one month's treatment, the fatal toxicity index of venlafaxine suggests that it will cause a death from poisoning about every 6000 patient years of use. Clinicians need to consider whether factors in their patients reduce or compensate for this risk before prescribing venlafaxine.

We thank Zoe Uren of the Office for National Statistics; Graham Jackson of the General Register Office for Scotland; Bill Gold of ISD, Primary Care Information Unit, Scotland; Andy Savva of the Statistics Division of the Department of Health, England; and Sandra Hennefer, information officer at Health Solutions, Wales, for supplying the data on which this analysis is based.

Contributors: NB drafted the paper and performed the statistical analyses. Both authors performed data extraction, wrote the paper, and agreed on the final version. NB is the guarantor.
Funding: None.

Competing interests: None declared.

1 Buckley NA, McManus PR. Can the fatal toxicity of antidepressant drugs be predicted with pharmacological and toxicological data? Drug Saf 1998;18:369-81.

2 Henry JA, Alexander CA, Sener EK. Relative mortality from overdose of antidepressants. BMJ 1995;310:221-4.

3 Sarko J. Antidepressants, old and new: a review of their adverse effects and toxicity in overdose. Emerg Med Clin North Am 2000;18:637-54.

4 Isacsson G, Redfors I, Wasserman D, Bergman U. Choice of antidepressants: questionnaire survey of psychiatrists and general practitioners in two areas of Sweden. BMJ 1994:309:1546-9.

5 Owens D, Dennis M, Read S, Davis N. Outcome of deliberate self-poisoning: an examination of risk factors for repetition. BrJ Psychia try 1994;165:797-801.

(Accepted 4 October 2002)

\section{Drug points}

\section{Leflunomide can potentiate the anticoagulant effect of warfarin}

V Lim, I Pande

Leflunomide (Arava; Aventis Pharma) is used widely to treat inflammatory arthritis. We report a case of a probable interaction between leflunomide and warfarin.

A 49 year old man with resistant rheumatoid arthritis started taking leflunomide at the recommended loading dose of $100 \mathrm{mg}$ daily for three days. His international normalised ratio had been stable for a year while he was taking warfarin, and two days before starting treatment with leflunomide it was 3.4. After he took the second dose of leflunomide, he developed gross haematuria, for which he required hospital admission. His international normalised ratio had risen to 11 , and warfarin was discontinued. His haemoglobin concentration was satisfactory and the haematuria spontaneously resolved several hours after admission. His ratio remained raised for the next two days, even though he had stopped taking warfarin, and he was given $1 \mathrm{mg}$ of vitamin $\mathrm{K}$ intravenously on the third day. Twelve hours later, the ratio decreased to 1.9 (figure), which coincided with the change to the leflunomide maintenance dose of $20 \mathrm{mg}$ daily. Subsequently he began taking warfarin again but at a lower dose of $1 \mathrm{mg}$ daily, which was sufficient to maintain his international normalised ratio within the recommended range.

Leflunomide was considered to have caused the increase in the patient's international normalised ratio. Such a role for leflunomide is supported by the temporal relation to the abnormal ratio and the subsequent lower warfarin doses required to maintain the ratio within the normal range. A rechallenge was not possible or ethical.

Leflunomide is rapidly converted to the active metabolite A771726 by first pass metabolism in the gut wall and liver. A771726 inhibits cytochrome P-4502C9 and can increase the bioavailability of drugs metabolised by cytochrome $P-4502 \mathrm{C} 9$, such as warfarin and phenytoin. This is important as many patients with inflammatory arthritis also take warfarin. The interaction between leflunomide and warfarin was not detected in clinical trials ${ }^{12}$ nor is it mentioned in the British National Formulary. ${ }^{3}$ We found no published reports of an interaction between leflunomide and warfarin.

The first information booklet for healthcare professionals on leflunomide ${ }^{4}$ implied that it was metabolised by

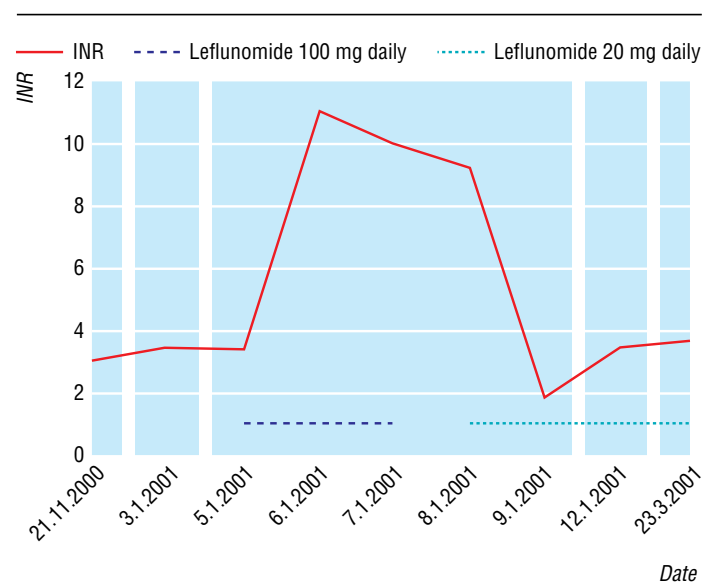

Rheumatology Department, Nottingham City Hospital, Nottingham NG5 1PB

V Lim

I Pande

Correspondence to:

V Lim

vunroei@

hotmail.com

BMJ 2002;325:1333

International normalised ratio (INR) in relation to leflunomide treatment

cytochrome P-4502C9 and its effects may be increased, rather than decreased, by warfarin. This was contrary to the pharmacokinetics, according to the summary of product characteristics for Arava. ${ }^{5}$ We informed our hospital drug information department, the Committee on Safety of Medicines, and Aventis Pharma. The Committee on Safety of Medicines had received over 300 reports of raised international normalised ratio in patients taking leflunomide concurrently with warfarin. Aventis Pharma has released CD Roms (Information for professionals and Information for patients), which contain the correct drug information.

Funding: None.

Competing interests: None declared.

1 Mladenovic V, Domljian Z, Rozman B, Jajic I, Mihajlovic D, Dordevis J, et al. Safety and effectiveness of leflunomide in the treatment of patient with active rheumatoid arthritis: results of a randomised, placebocontrolled, phase II study. Arthritis Rheum 1995;38:1595-603.

2 Blaz Rozman for the Leflunomide Investigators' Group. Clinical experience with leflunomide in rheumatoid arthritis. I Rheumatol 1998;25(suppl 53):27-32S

3 British Medical Association, Royal Pharmaceutical Society of Great Britain. British national formulary. London: BMA, RPS, March 2001 (No 41).

4 Leflunomide information booklet for healthcare professionals-questions and answers. Uxbridge: Hoechst Marion Roussel, 1999.

5 Summary of product characteristics for Arava. Uxbridge: Hoechst Marion Roussel, 1999. 